\title{
Decreased survival among lung cancer patients with co-morbid tuberculosis and diabetes
}

\author{
Shwn-Huey Shieh ${ }^{1,2}$, Janice C Probst ${ }^{3}$, Fung-Chang Sung ${ }^{4,5}$, Wen-Chen Tsai ${ }^{1}$, Ya-Shin Li ${ }^{6}$ and Chih-Yi Chen ${ }^{7,8^{*}}$
}

\begin{abstract}
Background: Comorbid conditions influence the survival of cancer patients. This study evaluated the influence of comorbidity on survival among lung cancer patients.

Methods: The authors evaluated the medical records of 1111 lung cancer patients of a medical center in Taiwan. Days of survival were calculated for each patient and mortality hazard ratios were estimated for associations with demographic status, comorbidity and cancer stage at diagnosis.

Results: On average, the survival time was slightly longer among women than among men (838 $\pm 689 \mathrm{vs.}$ $749 \pm 654$ days, $p=0.050$ ). Survival days increased with age (from $580 \pm 526[\leq 50$ years] to $803 \pm 693$ [ $\geq 71$ years] days, $p=0.020$ ) and decreased with stage (from $1224 \pm 656$ [stage I] to $489 \pm 536$ [stage IV] days, $p<0.001$ ). Younger patients were more likely to be diagnosed with lung cancer at a late stage. Compared with lung cancer patients without tuberculosis, those with tuberculosis had a significantly shorter average survival duration (584 vs. 791 days, $p=0.002)$ and a higher mortality hazard ratio (1.30,95\% Cl: $1.03-1.65)$. A similar trend was observed in lung cancer patients with diabetes.
\end{abstract}

Conclusions: Lung cancer patients with comorbid tuberculosis or diabetes are at an elevated risk of mortality. These patients deserve greater attention while undergoing cancer treatment.

Keywords: Lung cancer, Comorbidity, Diabetes, Survival, Tuberculosis

\section{Background}

Cancer is a highly complicated disease. Cancer survival mainly depends on patient characteristics, the histology and pathology of the tumor, stage at diagnosis, hosttumor interaction, and comorbidities. Comorbidity has an inherent influence on each patient's initial treatment and the treatment effectiveness of patient care. Previous studies have demonstrated that less aggressive treatment is given to patients with breast cancer, prostate cancer, lymphoma, or lung cancer who have specific existing comorbidities [1-6]. Several diseases such as hypertension, ischemic heart disease, cerebrovascular disease, chronic obstructive pulmonary disease (COPD), and diabetes mellitus (DM) are considered to have a significant influence on the survival of cancer patients [2,7-10].

\footnotetext{
* Correspondence: micc@www.cmuh.org.tw

${ }^{7}$ Department of Respiratory Therapy, China Medical University, Taichung 40402, Taiwan

${ }^{8}$ Cancer center, China Medical University Hospital, 2 Yu Der Road, Taichung 40402, Taiwan

Full list of author information is available at the end of the article
}

In the case of lung cancer patients, pulmonary and cardiovascular function may have a significant impact on survival [2,11-14]. Elderly patients with Stage I or II lung cancer are less likely to receive surgery than younger patients [13]. Patients with COPD, cardiovascular disease, or DM comorbidity also have a lower resection rate [13]. Janssen-Heijnen et al. reported that the morbidity and mortality of non-small cell lung cancer (NSCLC) patients following resection are associated with poor pulmonary function or cardiovascular disease [2]. Older NSCLC patients have a higher prevalence of comorbid cardiovascular disease or COPD, which may cause additional morbidity and reduce their survival. Battafarano et al. indicated that NSCLC patients with comorbidity have a two-fold increased risk of death compared with patients without comorbidity [11].

The presence of multiple comorbid diseases is common among lung cancer patients, with $22.1 \%$ of patients having five or more comorbid diseases, $54.3 \%$ having three or more, and $88.3 \%$ having one or more [14-16].

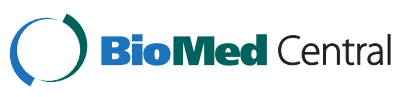


Tammemagi et al. have reported that tuberculosis (TB), COPD, and DM are the most common comorbidities associated with a reduced survival among patients with lung cancer [14]. They also identified that comorbidity is important for predicting the survival of both localized and advanced lung cancer [16].

The symptoms of lung cancer can be masked by the symptoms of comorbid diseases such as chronic bronchitis, COPD, TB, DM, hypertension (HT), or even heart disease $[15,17,18]$. Patients with comorbid diseases may ignore symptoms or delay reporting them to a physician, because the symptoms of lung cancer are often confused with those of comorbid diseases. Comorbid diseases may exert direct effects on the host immune system and reduce the duration of survival, and are thus among the most important factors for determining lung cancer survival $[19,20]$.

The objective of this study was to investigate the influence of comorbidity on the survival of patients with lung cancer. Furthermore, we presented data showing the associations between selected comorbid diseases (TB, $\mathrm{DM}, \mathrm{HT}, \mathrm{COPD}$, and other cancer $[\mathrm{OC}]$ ) and survival.

\section{Materials and methods \\ Sample}

Data on the care of 1410 patients newly diagnosed with histologically confirmed lung cancer between October 1997 and December 2004 at a medical center in central Taiwan were extracted from the medical records of 2516 lung cancer patients by three trained medical nurses. Group I included all lung cancer patients with resectable tumors $(n=626)$ who had received surgery at the Department of Thoracic Surgery. Group II comprised 784 patients with late-stage lung cancer who were randomly selected from 1890 patients cared for at the Departments of Chest Medicine and Radiotherapy. There were no significant differences between the 784 randomly selected patients and those not selected in terms of age $(p=0.309)$ or $\operatorname{sex}(p=0.804)$.

Among the 1410 patients in groups I and II, 299 were excluded from the analysis because they had incomplete baseline information (for example, missing personal ID or unknown cancer stage), metastatic cancer from other organs or postoperative deaths. The remaining 1111 patients were included in the data analysis. This study was approved by the Institutional Review Boards of the medical center.

\section{Variable definitions}

\section{Survival}

The number of days lived after the initial diagnosis was recorded. Patients' vital status information was obtained from the official death registry. Patients were followed for more than 7 years or until deceased.

\section{Comorbidity}

Comorbidity was the disease present at the time of lung cancer diagnosis. We adopted the method developed by Charlson et al. to select comorbidities with potential association with lung cancer survival. These were OC, TB, DM, HT, and COPD [21].

\section{Stage of the disease}

The stage at diagnosis of each lung cancer case was defined in accordance with the classification outlined in the American Joint Committee on Cancer's Cancer Staging Manual [22]. In Stage I, the cancer is in the lung only, with normal tissue around the tumor. In Stage II, the cancer has spread to nearby lymph nodes or the chest wall, diaphragm, mediastinal pleura, or parietal pericardium. In Stage III, the cancer has either spread to the lymph nodes in the mediastinum (N2; Stage IIIa) or to the lymph nodes on the opposite side of the chest or in the lower neck (N3; Stage IIIb). Stage III is locally advanced lung cancer. For the purpose of this study, patients with Stage IIIa or IIIb lung cancer are combined into a single group. In Stage IV, the cancer has spread to other parts of the body or to another lobe of the lungs. A physician checked the pathology or cytology reports and the clinical image studies to confirm the tumor stage diagnosis.

\section{Control variables}

Patients' demographic characteristics (age, sex, religion, education, marital status, and occupation) with implications for survival were controlled for in the multivariate analyses.

\section{Data analysis}

Data analyses first used descriptive statistical analyses to identify the mean, median and interquartile ranges of survival duration by sociodemographic status, comorbidity and cancer stage at diagnosis. Survival duration was compared between men and women, among age groups ( $\leq 50,51-60,61-70$ and $\geq 71$ years), other demographic variables, among patients with and without the selected comorbidity (OC, TB, COPD, DM and HT), and among lung cancer stages. Mean days of survival were also estimated to evaluate the interactions between comorbidities and cancer stages. Multivariate Cox proportional hazards regression was used to compute the adjusted lung cancer mortality hazard ratios (HR) and 95\% confidence intervals (CI). Lung cancer mortality HRs were calculated separately for men and women, different age groups, patients with or without a specific comorbidity and different cancer stages. We also used a KaplanMeier model to compare patient survival rates between those with and without a comorbidity that was significantly associated with the duration of survival. Analyses 
Table 1 Means, medians and interquartile ranges of survival days in patients with lung cancer by patient characteristics, co-morbidity and stage of disease

\begin{tabular}{|c|c|c|c|c|c|c|}
\hline \multirow[t]{2}{*}{ Criteria } & \multicolumn{2}{|c|}{$\mathrm{N}=1111$} & \multicolumn{3}{|c|}{ Survival Days } & \multirow{2}{*}{$\begin{array}{l}P \text {-value for } \\
\text { means }\end{array}$} \\
\hline & $n$ & $\%$ & Median & 25th - 75th & Mean \pm SD & \\
\hline Overall & 1111 & $(100)$ & 624 & $205-1190$ & $772 \pm 665$ & \\
\hline \multicolumn{7}{|l|}{ Age } \\
\hline$\leq 50$ & 94 & $(8.5)$ & 419 & $188-864$ & $580 \pm 526$ & 0.020 \\
\hline $51-60$ & 155 & (14.0) & 597 & $234-1039$ & $738 \pm 641$ & \\
\hline $61-70$ & 290 & $(26.1)$ & 699 & $244-1228$ & $792 \pm 651$ & \\
\hline$\geq 71$ & 572 & $(51.5)$ & 654 & $187-1268$ & $803 \pm 693$ & \\
\hline \multicolumn{7}{|l|}{ Gender } \\
\hline Male & 822 & $(74.0)$ & 596 & $188-1152$ & $749 \pm 654$ & 0.050 \\
\hline Female & 289 & (26.0) & 711 & $259-1279$ & $838 \pm 689$ & \\
\hline \multicolumn{7}{|l|}{ Marital Status } \\
\hline Married & 964 & $(88.1)$ & 626 & $216-1200$ & $780 \pm 666$ & 0.112 \\
\hline Single (included divorce) & 130 & (11.9) & 529 & $123-971$ & $682 \pm 636$ & \\
\hline \multicolumn{7}{|l|}{ Education } \\
\hline$<$ Junior high & 654 & $(63.3)$ & 556 & $185-1187$ & $756 \pm 681$ & 0.397 \\
\hline Junior high & 137 & (13.3) & 647 & $211-1163$ & $751 \pm 611$ & \\
\hline Senior high & 171 & (16.6) & 697 & $271-1287$ & $842 \pm 681$ & \\
\hline$\geq$ College & 71 & (6.9) & 528 & $201-1115$ & $707 \pm 623$ & \\
\hline \multicolumn{7}{|l|}{ Religion } \\
\hline No & 294 & (28.0) & 651 & $182-1163$ & $763 \pm 662$ & 0.847 \\
\hline Yes & 755 & $(72.0)$ & 615 & $211-1193$ & $772 \pm 666$ & \\
\hline \multicolumn{7}{|l|}{ Occupation } \\
\hline Work & 323 & (30.0) & 554 & $188-1122$ & $744 \pm 662$ & 0.378 \\
\hline Retired & 296 & $(27.5)$ & 555 & $177-1170$ & $743 \pm 672$ & \\
\hline Not work & 457 & $(42.5)$ & 715 & $233-1202$ & $801 \pm 654$ & \\
\hline \multicolumn{7}{|l|}{ Comorbidity } \\
\hline \multicolumn{7}{|l|}{ Other cancer } \\
\hline No & 1031 & $(94.2)$ & 606 & $201-1180$ & $764 \pm 666$ & 0.116 \\
\hline Yes & 64 & (5.8) & 813 & $350-1376$ & $898 \pm 643$ & \\
\hline \multicolumn{7}{|l|}{ Tuberculosis } \\
\hline No & 989 & (90.3) & 653 & $220-1206$ & $791 \pm 667$ & 0.002 \\
\hline Yes & 106 & $(9.7)$ & 364 & $107-856$ & $584 \pm 612$ & \\
\hline \multicolumn{7}{|l|}{ COPD } \\
\hline No & 1040 & (95.0) & 614 & $206-1176$ & $765 \pm 662$ & 0.162 \\
\hline Yes & 55 & $(5.0)$ & 863 & $317-1353$ & $894 \pm 714$ & \\
\hline \multicolumn{7}{|l|}{ Diabetes } \\
\hline No & 967 & (88.3) & 651 & $220-1220$ & $794 \pm 670$ & 0.001 \\
\hline Yes & 128 & (11.7) & 427 & $134-929$ & $600 \pm 601$ & \\
\hline \multicolumn{7}{|l|}{ Hypertension } \\
\hline No & 808 & (73.8) & 654 & $220-1219$ & $788 \pm 660$ & 0.178 \\
\hline Yes & 287 & $(26.2)$ & $>546$ & $169-1122$ & $726 \pm 677$ & \\
\hline
\end{tabular}


Table 1 Means, medians and interquartile ranges of survival days in patients with lung cancer by patient characteristics, co-morbidity and stage of disease (Continued)

\begin{tabular}{clllll}
\hline Stage & & & & & \\
I & 216 & $(19.4)$ & 1164 & $743-1681$ & $1224 \pm 656$ \\
II & 106 & $(9.5)$ & 913 & $546-1498$ & $1045 \pm 674$ \\
III & 406 & $(36.5)$ & 555 & $220-1073$ & $727 \pm 622$ \\
IV & 383 & $(34.5)$ & 273 & $94-723$ & $489 \pm 536$ \\
\hline
\end{tabular}

COPD: chronic obstructive pulmonary disease.

were performed using the SAS Statistics System (Version 9.1, SAS Institute Inc., Cary, NC).

\section{Results}

\section{Comparison of survival duration}

The patients included in the analysis were mostly male, elderly, and married. Most patients had a low educational attainment and a high proportion of religious affiliation (Table 1). Overall, the mean survival duration was $772 \pm 665$ days, with a median of 624 days and interquartile range of 205-1190 days. Survival medians were consistently lower than survival means for all investigated variables. Survival duration was longer in women than in men, and increased with age, with mean from $580 \pm 526$ days for $\leq 50$ years group to $803 \pm 693$ days for $\geq 71$ years group $(p=0.020)$. Survival duration was not significantly associated with education level, religion or job status. Table 1 also shows that almost half the patients had at least one comorbid disease at baseline. The most prevalent comorbidity was HT (26.2\%), followed by DM (11.7\%), TB (9.7\%), OC (5.8\%) and COPD (5.0\%). On average, patients with comorbid OC or COPD had a longer duration of survival, but this was not a statistically significant difference. Those with comorbid tuberculosis $(p=0.002)$, diabetes $(p=0.001)$ or hypertension $(\mathrm{p}=0.178)$ had a shorter duration of survival. Patient survival duration decreased with advancing cancer stage, from an average of 1224 days for those diagnosed with stage I to 489 days for those diagnosed with stage IV cancer.

\section{Survival duration by comorbidity and cancer stage}

Table 2 shows the mean survival duration for lung cancer patients by comorbidity and cancer stage. In general, the mean survival duration decreased with advancing cancer stage. Patients with a comorbidity tended to have a shorter survival duration, except for those with comorbid COPD or HT who were diagnosed with lung cancer at an early stage. On average, patients with comorbid TB or DM had a shorter survival duration than patients without the corresponding diseases among all stages. The Kaplan-Meier analysis showed that 7-year survival rates were $11 \%$ lower for patients with $\mathrm{TB}$ than for patients without TB (10\% vs. 21\%) (Figure 1) and 7\% less for patients with DM than for patients without DM (14\% vs. $21 \%$ ) (Figure 2 ).

\section{Mortality hazard ratio}

The results of the multivariate Cox proportional hazards analysis shows that men were at higher risk of death than women $(\mathrm{HR}=1.44,95 \% \mathrm{CI}=1.20-1.72$, Table 3$)$. The HRs were not significantly different among age groups. Patients with comorbid TB had a HR of 1.30 (95\% CI $=1.03-1.65)$. Those with comorbid DM also had a higher risk of death $(\mathrm{HR}=1.44,95 \% \mathrm{CI}=1.15-1.80)$ during the observation period. Patients with comorbid OC, COPD or HT did not have a higher risk of death

Table 2 Baseline prevalence of comorbidity among lung cancer patients and mean survival days by comorbidity and stage of lung cancer at diagnosis

\begin{tabular}{|c|c|c|c|c|c|}
\hline \multirow[t]{3}{*}{ Comorbidity } & \multicolumn{4}{|l|}{ Stage } & \multirow{3}{*}{$\begin{array}{l}P \text { - } \\
\text { value }\end{array}$} \\
\hline & I & II & III & IV & \\
\hline & $N=214$ & $N=104$ & $N=399$ & $N=378$ & \\
\hline
\end{tabular}

Other cancer

$\begin{array}{llllllllll}\text { No } & 91.6 & 1235 & 96.2 & 1072 & 94.7 & 718 & 94.4 & 467 & - \\ \text { Yes } & 8.4 & 1157 & 3.8 & 334 & 5.3 & 829 & 5.6 & 853 & 0.093 \\ \text { Tuberculosis } & & & & & & & & & \\ \text { No } & 92.5 & 1247 & 89.4 & 1075 & 90.2 & 743 & 89.4 & 500 & - \\ \text { Yes } & 7.5 & 1002 & 10.6 & 774 & 9.8 & 553 & 10.6 & 395 & 0.004 \\ \text { COPD } & & & & & & & & & \\ \text { No } & 92.1 & 1213 & 94.2 & 1038 & 95.5 & 726 & 96.3 & 491 & - \\ \text { Yes } & 7.9 & 1408 & 5.8 & 1123 & 4.5 & 685 & 3.7 & 435 & <0.001\end{array}$

Diabetes

\begin{tabular}{llllllllll} 
No & 86.9 & 1280 & 90.4 & 1065 & 88.7 & 752 & 88.1 & 492 & - \\
Yes & 13.1 & 889 & 9.6 & 836 & 11.3 & 503 & 11.9 & 466 & 0.008 \\
Hypertension & & & & & & & & & \\
No & 70.1 & 1209 & 77.9 & 1111 & 75.4 & 757 & 73.0 & 498 & - \\
Yes & 29.9 & 1275 & 22.1 & 806 & 24.6 & 622 & 27.0 & 465 & $<0.001$ \\
\hline
\end{tabular}

Mean: Average of survival days.

COPD: chronic obstructive pulmonary disease.

Missing data: 16 cases. 


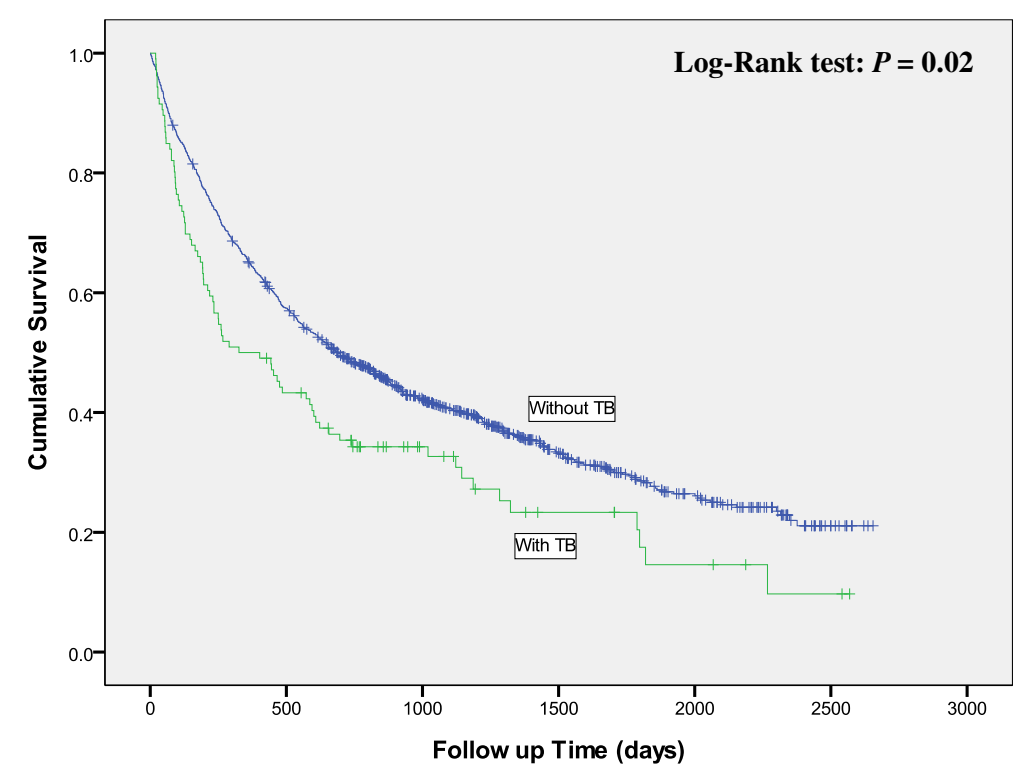

Figure 1 The comparison of survival time between lung cancer patient with or without TB.

than patients without the corresponding comorbidity. The adjusted analysis showed that the stage at diagnosis had a significant association with survival. Using Stage I as the reference, the risk of death was markedly higher among patients diagnosed at advanced cancer stages (Stage II: $\mathrm{HR}=1.85,95 \% \mathrm{CI}=1.30-2.61$; Stage III: $\mathrm{HR}=$ $3.35,95 \% \mathrm{CI}=2.57-4.35$; Stage IV: $\mathrm{HR}=5.63,95 \% \mathrm{CI}=$ $4.32-7.33)$.

\section{Discussion}

This study examined how patient characteristics and selected comorbidities are associated with survival for patients with lung cancer. Patients with comorbid TB or DM had a reduced duration of survival, and a higher mortality hazard. Younger patients had a shorter survival duration than older patients, a phenomenon has not been previously reported.

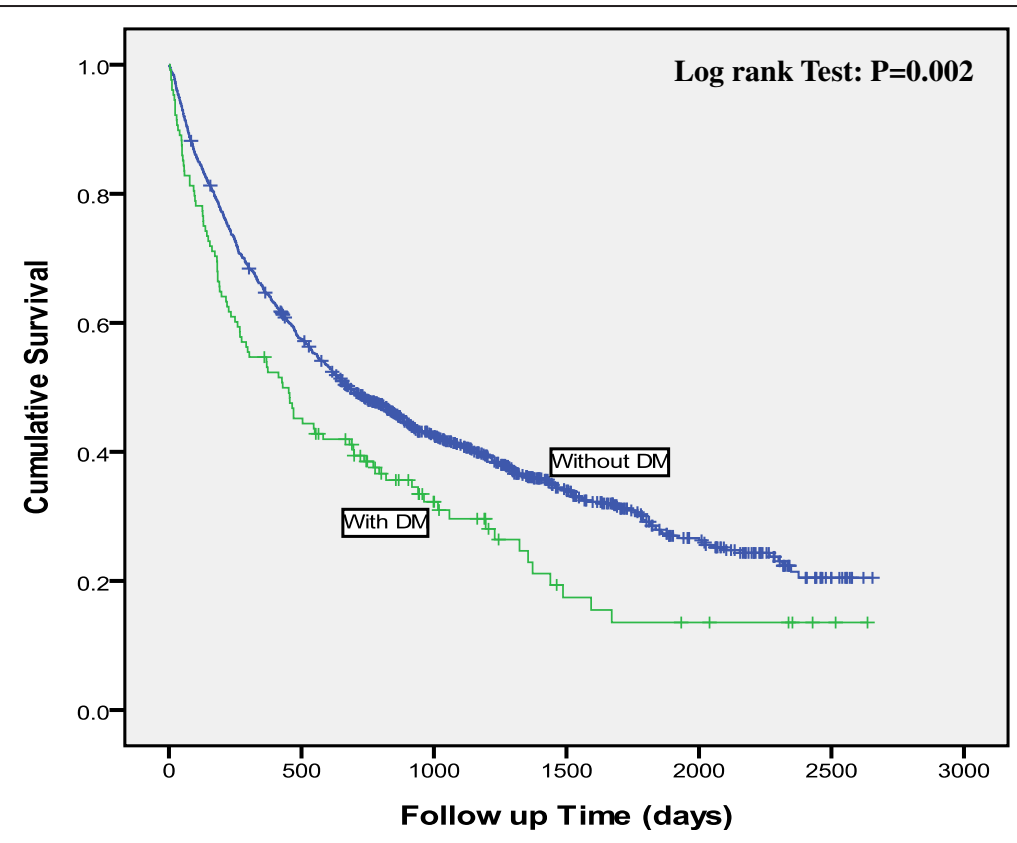

Figure $\mathbf{2}$ The comparison of survival time between lung cancer patient with or without DM. 
Table 3 Mortality rate and multivariable Cox proportional hazards regression model measured hazard ratio (HR) and $\mathbf{9 5 \%}$ confidence interval $(\mathrm{Cl})$ of mortality by demographic status, co-morbidity and stage of lung cancer

\begin{tabular}{|c|c|c|c|c|c|c|c|c|c|}
\hline $\begin{array}{l}\text { Variables } \\
\text { Overall }\end{array}$ & $\frac{\mathbf{N}}{1111}$ & $\begin{array}{l}\text { Death } \\
738\end{array}$ & \multirow{2}{*}{$\begin{array}{l}\text { Person-days } \\
857762\end{array}$} & \multirow{2}{*}{$\begin{array}{l}\text { Mortality rate } \\
0.86\end{array}$} & \multicolumn{2}{|c|}{ Rate ratio $(95 \% \mathrm{Cl})$} & \multicolumn{2}{|c|}{ HRs* $^{*}(95 \% \mathrm{Cl})$} & \multirow[t]{2}{*}{$p$-value } \\
\hline & & & & & & & & & \\
\hline \multicolumn{10}{|l|}{ Gender } \\
\hline Male & 822 & 565 & 615638 & 0.92 & 1.28 & $(1.08-1.52)$ & 1.44 & $(1.20-1.72)$ & $<0.001$ \\
\hline Female & 289 & 173 & 242124 & 0.71 & 1.00 & & 1.00 & & \\
\hline \multicolumn{10}{|l|}{ Age, years } \\
\hline$\leq 50$ & 94 & 68 & 54514 & 1.25 & 1.47 & $(1.14-1.90)$ & 1.29 & $(0.99-1.70)$ & 0.064 \\
\hline $51-60$ & 155 & 98 & 114428 & 0.86 & 1.01 & $(0.81-1.26)$ & 0.89 & $(0.71-1.12)$ & 0.328 \\
\hline $61-70$ & 290 & 183 & 229726 & 0.80 & 0.94 & $(0.79-1.12)$ & 1.00 & $(0.83-1.20)$ & 0.994 \\
\hline$\geq 71$ & 572 & 389 & 459094 & 0.85 & 1.00 & & 1.00 & & \\
\hline \multicolumn{10}{|c|}{ Comorbidity } \\
\hline \multicolumn{10}{|c|}{ Other Cancer } \\
\hline No & 1031 & 690 & 787641 & 0.88 & 1.00 & & 1.00 & & \\
\hline Yes & 64 & 38 & 57496 & 0.66 & 0.75 & $(0.54-1.05)$ & 0.77 & $(0.55-1.07)$ & 0.124 \\
\hline \multicolumn{10}{|c|}{ Tuberculosis } \\
\hline No & 989 & 649 & 783186 & 0.83 & 1.00 & & 1.00 & & \\
\hline Yes & 106 & 79 & 61951 & 1.28 & 1.54 & $(1.22-1.94)$ & 1.30 & $(1.03-1.65)$ & 0.030 \\
\hline \multicolumn{10}{|l|}{ COPD } \\
\hline No & 1040 & 696 & 795978 & 0.87 & 1.00 & & 1.00 & & \\
\hline Yes & 55 & 32 & 49159 & 0.65 & 0.74 & $(0.52-1.06)$ & 0.97 & $(0.67-1.38)$ & 0.848 \\
\hline \multicolumn{10}{|l|}{ Diabetes } \\
\hline No & 967 & 633 & 768281 & 0.82 & 1.00 & & 1.00 & & \\
\hline Yes & 128 & 95 & 76856 & 1.24 & 1.50 & $(1.21-1.86)$ & 1.44 & $(1.15-1.80)$ & 0.002 \\
\hline \multicolumn{10}{|c|}{ Hypertension } \\
\hline No & 808 & 534 & 636661 & 0.84 & 1.00 & & 1.00 & & \\
\hline Yes & 287 & 194 & 208476 & 0.93 & 1.11 & $(0.94-1.31)$ & 1.07 & $(0.90-1.27)$ & 0.453 \\
\hline \multicolumn{10}{|l|}{ Stage } \\
\hline । & 216 & 73 & 264485 & 0.28 & 1.00 & & 1.00 & & \\
\hline$\|$ & 106 & 60 & 110785 & 0.54 & 1.96 & $(1.39-2.76)$ & 1.85 & $(1.30-2.61)$ & 0.001 \\
\hline III & 406 & 289 & 295328 & 0.98 & 3.55 & $(2.74-4.58)$ & 3.35 & $(2.57-4.35)$ & $<0.001$ \\
\hline IV & 383 & 316 & 187164 & 1.69 & 6.12 & $(4.74-7.89)$ & 5.63 & $(4.32-7.33)$ & $<0.001$ \\
\hline$p$ for trend & & & & & & & $<0.0$ & & \\
\hline
\end{tabular}

COPD: chronic obstructive pulmonary disease.

* Adjusted Hazard Ratios, obtained with statistical adjustment for all the variables listed in this table.

Previous studies have shown that patient demographic characteristics such as age, sex, marital status, and education are important factors associated with cancer survival $[13,17,23-26]$. We found sex to be significantly associated with survival in the multivariate analysis (Table 3). Men had a shorter survival duration than women and an approximately $44 \%$ increased mortality hazard. This result is consistent with other studies $[16,27,28]$. It is generally recognized that lung cancer survival among women is far better than that among men $[27,28]$. Lung cancer is biologically different in men and women. The biological characteristics and prognostic profiles of the tumor may also differ between them [26-28]. Approximately only 4.0-9.0\% of women are smokers in Taiwan. Female patients are more likely to have never smoked than male patients $[29,30]$. Taiwanese women are also more likely than men to present with adenocarcinoma rather than squamous carcinoma of the lung [31].

Education, religion, marital status, and occupation were not found to be significantly related to survival in the adjusted analysis. Several previous studies have found a significant association between age and survival $[13,23,24,26]$. We found that younger patients had a 
shorter survival in both the crude and adjusted analyses. A further analysis using a contingency table of age by stage showed that a greater proportion of younger patients ( $\leq 50$ years) than older patients had their lung cancer diagnosed at a late stage $(47.9 \%$ vs. $30.1 \%$ in stage IV) (data not shown). This late detection is likely to explain why the younger patients had a much shorter survival duration than the oldest group of patients $(580 \pm 526$ vs. $803 \pm 693$ days on average). Young patients are apparently unaware of the importance of early detection. They are also more likely to be heavy smokers [16,32].

The lung cancer survival duration was also found to be determined by the stage of disease, tumor biology and comorbidity. Comorbidity is not only an independent prognostic factor for surgical resection, but also important in host-resistance and host-tumor interaction, and has a significant role in survival $[2,11-13,19]$.

Only a few studies have investigated the association between comorbidity and lung cancer survival. Tammemagi et al. and Battafarano et al. found support for the hypothesis that comorbidity is inversely related to survival duration [11,14]. Several studies found that TB, $\mathrm{DM}, \mathrm{OC}, \mathrm{COPD}$ and peripheral vascular disease may independently predict reduced survival duration $[9,14]$. Our study also found that lung cancer patients with comorbid TB or DM have a shorter survival duration across all stages of lung cancer. However, some other studies have contradictory findings. Janssen-Heijnen et al. reported that comorbidity was not a significant factor determining cancer survival [13]. Poorer survival among patients with TB or DM, even with stage at initial diagnosis held constant, may stem from less efficient immunization, anti-tumor defense systems, and multiple organ dysfunctions with these conditions. Poorer lung function, physical performance status, and nutrition, as well as lower immunization among lung cancer patients with TB may influence the available treatment choices $[19,20]$. Furthermore, the chronic cough caused by TB may cause patients to be ignorant their lung cancer and delay them from seeking medical treatment, thus influencing their survival.

The current clinical evaluation of treatment effectiveness and the care of lung cancer patients put more emphasis on cancer stage and tumor biology, while ignoring other patient characteristics. Comorbidities may influence the choice of treatment and treatment side effects, which are associated with patient survival. Therefore, physicians should carefully evaluate each patient's comorbidities. In the present study, 9.7\% of the lung cancer patients had TB. TB patients are at higher risk of developing lung cancer. Yu et al. found that patients with pulmonary TB are at 11-fold higher risk of developing lung cancers than those without TB [33]. Therefore, it is necessary to examine the respiratory tract symptoms of patients with TB to screen for lung cancer and improve their survival. DM is one of the world's major chronic diseases and leading causes of death. DM patients have poor nutrition absorption, and are at risk of higher glucose and immunization, which may also lead to limited treatment choices and reduced survival $[2,7-10]$.

\section{Conclusions}

In conclusion, this study suggests that lung cancer patients with comorbidity, particularly DM or TB deserve more attention while undergoing cancer treatment. In addition, having a valid disease-specific instrument to measure and classify the overall severity of comorbidity is very important for improving the outcome of lung cancer care, especially for long-term survival. This study also observed shorter survival durations among young patients. More attention should be devoted to these patients, who may have had the disease diagnosed at a late stage.

Our findings reflect the importance of public health in reducing the prevalence of comorbidities and late diagnosis among lung cancer patients. However, the biological and/or appropriate therapeutic implications of comorbidities for lung cancer have not been addressed in this study. They remain important issues for future study. Further investigations focusing on caring for lung cancer patients with comorbid diseases such as TB or DM are needed to provide direction for clinicians treating patients with comorbid conditions.

\section{Acknowledgements}

The authors would like to thank Dr. Jiun-Yi Hsia for his assistance in the provision of professional input throughout the course of this study. This study was supported in part by Department of Health Cancer Research Cancer of Excellence, Taiwan (DOH100-TD-C111-005), Clinical Trial and Research Center of Excellence (DOH100-TD-B111-004), and China Medical University Hospital (1MS1).

\section{Author details \\ 'Department of Health Services Administration, China Medical University, Taichung 40402, Taiwan. ${ }^{2}$ Department of Nursing, China Medical University Hospital, Taichung 40402, Taiwan. ${ }^{3}$ Department of Health Services Policy and Management, Arnold School of Public Health, University of South Carolina, Columbia, SC, USA. ${ }^{4}$ Department of Public Health, China Medical University, Taichung 40402, Taiwan. ${ }^{5}$ Department of Medical Research, China Medical University Hospital, Taichung40402, Taiwan. ${ }^{6}$ Department of Health Systems Management, Chung-Shan Medical University and Hospital, Taichung 40201, Taiwan. 'Department of Respiratory Therapy, China Medical University, Taichung 40402, Taiwan. ${ }^{8}$ Cancer center, China Medical University Hospital, 2 Yu Der Road, Taichung 40402, Taiwan.}

\section{Conflicting interests}

There are no potential conflicts of interest for any of the authors. All authors have no reportable conflicts.

\section{Authors' contributions}

$\mathrm{C}$ and $\mathrm{S}$ designed the study. $\mathrm{C}$ was involved in the provision of study materials and patients. S, P, T and L performed the data analysis and interpretation. $C$ and $S$ wrote the manuscript together with $P$ and $S$. All authors read and approved the final manuscript. 
Received: 7 October 2011 Accepted: 11 May 2012

Published: 11 May 2012

\section{References}

1. Asmis TR, Ding $K$, Seymour $L$, Shepherd FA, Leighl NB, Winton $T L$, Whitehead M, Spaans JN, Graham BC, Goss GD: Age and comorbidity as independent prognostic factors in the treatment of non small-cell lung cancer: a review of National Cancer Institute of Canada Clinical Trials Group trials. Journal of clinical oncology: official journal of the American Society of Clinical Oncology 2008, 26(1):54-59.

2. Janssen-Heijnen ML, Maas HA, Houterman S, Lemmens VE, Rutten $\mathrm{HJ}$, Coebergh JW: Comorbidity in older surgical cancer patients: influence on patient care and outcome. Eur J Cancer 2007, 43(15):2179-2193.

3. Lash TL, Thwin SS, Horton NJ, Guadagnoli E, Silliman RA: Multiple informants: a new method to assess breast cancer patients' comorbidity. Am J Epidemiol 2003, 157(3):249-257.

4. Ludbrook JJ, Truong PT, MacNeil MV, Lesperance M, Webber A, Joe H, Martins H, Lim J: Do age and comorbidity impact treatment allocation and outcomes in limited stage small-cell lung cancer? a communitybased population analysis. Int J Radiat Oncol Biol Phys 2003, 55(5): 1321-1330.

5. Post PN, Kil PJ, Hendrikx AJ, Janssen-Heijnen ML, Crommelin MA, Coebergh $\mathrm{JW}$ : Comorbidity in patients with prostate cancer and its relevance to treatment choice. BJU Int 1999, 84(6):652-656.

6. Satariano WA, Ragland DR: The effect of comorbidity on 3-year survival of women with primary breast cancer. Ann Intern Med 1994, 120(2):104-110.

7. Janssen-Heijnen ML, Schipper RM, Razenberg PP, Crommelin MA, Coebergh JW: Prevalence of co-morbidity in lung cancer patients and its relationship with treatment: a population-based study. Lung Cancer 1998, 21(2):105-113.

8. Ogle KS, Swanson GM, Woods N, Azzouz F: Cancer and comorbidity: redefining chronic diseases. Cancer 2000, 88(3):653-663.

9. Seshasai SR, Kaptoge S, Thompson A, Di Angelantonio E, Gao P, Sarwar N, Whincup PH, Mukamal KJ, Gillum RF, Holme I, et al: Diabetes mellitus, fasting glucose, and risk of cause-specific death. N Engl J Med 2011, 364 (9):829-841.

10. van Spronsen DJ, Janssen-Heijnen ML, Breed WP, Coebergh JW: Prevalence of co-morbidity and its relationship to treatment among unselected patients with Hodgkin's disease and non-Hodgkin's lymphoma, 19931996. Ann Hematol 1999, 78(7):315-319.

11. Battafarano RJ, Piccirillo JF, Meyers BF, Hsu HS, Guthrie TJ, Cooper JD, Patterson GA: Impact of comorbidity on survival after surgical resection in patients with stage I non-small cell lung cancer. J Thorac Cardiovasc Surg 2002, 123(2):280-287.

12. Budisin E: Comorbidity in Lung Cancer - Operated Patients, Impact on Survival and Prognosis, UICC World Cancer Congress. Washington, DC, USA: Evica Budisin; 2006

13. Janssen-Heijnen ML, Smulders S, Lemmens VE, Smeenk FW, van Geffen HJ, Coebergh JW: Effect of comorbidity on the treatment and prognosis of elderly patients with non-small cell lung cancer. Thorax 2004, 59(7): 602-607.

14. Tammemagi CM, Neslund-Dudas C, Simoff M, Kvale P: Impact of comorbidity on lung cancer survival. International journal of cancer Journal international du cancer 2003, 103(6):792-802.

15. Koyi H, Hillerdal G, Branden E: Patient's and doctors' delays in the diagnosis of chest tumors. Lung Cancer 2002, 35(1):53-57.

16. Tammemagi CM, Neslund-Dudas C, Simoff M, Kvale P: Smoking and lung cancer survival: the role of comorbidity and treatment. Chest 2004, 125 (1):27-37.

17. Hsu NY, Chen CY, Chung KP, Hsu CP, Hsia JY PYW: Pulmonary tuberculosis and lung cancer. Chin Med J 1996, 57(6):S140.

18. Piccirillo JF: Importance of comorbidity in head and neck cancer. Laryngoscope 2000, 110(4):593-602

19. Bergman L, Dekker G, van Kerkhoff EH, Peterse HL, van Dongen JA, van Leeuwen FE: Influence of age and comorbidity on treatment choice and survival in elderly patients with breast cancer. Breast cancer research and treatment 1991, 18(3):189-198.

20. Firat S, Bousamra M, Gore E, Byhardt RW: Comorbidity and KPS are independent prognostic factors in stage I non-small-cell lung cancer. Int J Radiat Oncol Biol Phys 2002, 52(4):1047-1057.
21. Charlson ME, Pompei P, Ales KL, MacKenzie CR: A new method of classifying prognostic comorbidity in longitudinal studies: development and validation. Journal of chronic diseases 1987, 40(5):373-383.

22. Fleming ID, Cooper JS, Henson DE, Hutter RVP, Kennedy BJ, Murphy GP, Sullivan BO, Sobin LH, JW Y: AJCC Cancer Staging Manual (5th ed.). Philadelphia: Lippincott-Raven Publishers; 1997.

23. Bibb SC: The relationship between access and stage at diagnosis of breast cancer in African American and Caucasian women. Oncology nursing forum 2001, 28(4):711-719.

24. Caplan LS, Helzlsouer KJ, Shapiro S, Freedman LS, Coates RJ, Edwards BK: System delay in breast cancer in whites and blacks. Am J Epidemiol 1995, 142(8):804-812.

25. Dayal HH, Power RN, Chiu C: Race and socio-economic status in survival from breast cancer. Journal of chronic diseases 1982, 35(8):675-683.

26. Porta M, Gallen M, Malats N, Planas J: Influence of "diagnostic delay" upon cancer survival: an analysis of five tumour sites. Journal of epidemiology and community health 1991, 45(3):225-230.

27. Moore KA, Mery CM, Jaklitsch MT, Estocin AP, Bueno R, Swanson SJ, Sugarbaker DJ, Lukanich JM: Menopausal effects on presentation, treatment, and survival of women with non-small cell lung cancer. Ann Thorac Surg 2003, 76(6):1789-1795.

28. Tammemagi CM, Neslund-Dudas C, Simoff M, Kvale P: In lung cancer patients, age, race-ethnicity, gender and smoking predict adverse comorbidity, which in turn predicts treatment and survival. Journal of clinical epidemiology 2004, 57(6):597-609.

29. Bureau of Tobacco and Alcohol Monopoly: Annual Report of Tobacco, Alcohol Consumption Investigation in Taiwan Area. Taipei: Taiwan Provincial Government; 1993

30. Ko YC, Lee CH, Chen MJ, Huang CC, Chang WY, Lin HJ, Wang HZ, Chang PY: Risk factors for primary lung cancer among non-smoking women in Taiwan. International journal of epidemiology 1997, 26(1):24-31.

31. Bureau of Health Promotion: Cancer Registry Annual Report, 2008. Taipei, Taiwan: Department of Health, The Executive Yuan; 2010.

32. Bureau of Health Promotion: Interactive Health Data Querying System. In. R.O. C. Taiwan: Department of Health; 2011.

33. Yu YH, Liao CC, Hsu WH, Chen HJ, Liao WC, Muo CH, Sung FC, Chen CY: Increased lung cancer risk among patients with pulmonary tuberculosis: a population cohort study. Journal of thoracic oncology: official publication of the International Association for the Study of Lung Cancer 2011, 6(1):32-37.

doi:10.1186/1471-2407-12-174

Cite this article as: Shieh et al:: Decreased survival among lung cancer patients with co-morbid tuberculosis and diabetes. BMC Cancer 2012 $12: 174$

\section{Submit your next manuscript to BioMed Central and take full advantage of:}

- Convenient online submission

- Thorough peer review

- No space constraints or color figure charges

- Immediate publication on acceptance

- Inclusion in PubMed, CAS, Scopus and Google Scholar

- Research which is freely available for redistribution 